\title{
A qualitative study on the role of patient- nurse communication in acute cardiac care
}

\author{
Maria Liljeroos $^{1,2}$, Ingrid M. Snellman ${ }^{3}$, Mirjam H. Ekstedt ${ }^{4,5}$ \\ 1. Department of Medicine, Mälar Hospital, Eskilstuna, Sweden. 2. Research and Development Center/Center for Clinical \\ Research Sörmland County Council, Eskilstuna, Sweden. 3. School of Health, Care and Social Welfare, Mälardalen \\ University, Eskilstuna, Sweden. 4. Department of Health care sciences, Ersta Sköndal University College, Stockholm, \\ Sweden. 5. School of Technology and Health, Royal Institute of Technology, Stockholm, Swedem
}

Correspondence: Mirjam H. Ekstedt, Address: Ersta Sköndal University, Dept of Health Care Sciences, Box: 11189 , SE-100 61 Stockholm, Sweden, Phone number: 46-855-505-096, Facsimile number: 46-855-505-070.

E-mail: mirjam.ekstedt@sth.kth.se

Received: August 11, 2011

Accepted: October 14, $2011 \quad$ Published: December 1, 2011

DOI : 10.5430/jnep.v1n1p17

URL: http://dx.doi.org/10.5430/jnep.v1n1p17

\section{Abstract}

Background: This study aimed to illuminate the meaning of the patient-nurse communication during a hospital stay as narrated by patients after a myocardial infarction (MI).

Methods: Narrative interviews from 10 patients were analyzed, using a phenomenological-hermeneutic method.

Results: The nursing dialogue meant a safe mooring point on the trajectory from initial chaos after a MI to a reoriented life. Nurses' presence and availability for non-verbal and verbal communication created a trustful relationship where new knowledge was acquired and motivational strength for life-style changes was mobilized. A person-centered perspective was preferred, where relatives were invited into the conversation.

Conclusions: These results highlight that patient-nurse communication based on the patient's view is possible in acute care after MI, and is an issue of attitude rather than time. Trust lays the foundation for a person-centered communication and is developed through the nurse's presence and availability not only in the emergency phase, but throughout hospitalization. Discussions focused on personal action plans with emphasis on the patient's health assets may facilitate a successful rehabilitation.

\section{Key words}

Acute cardiac care, Health assets, Myocardial infarction, Person-centered care, Relatives, Shared decision making, Trust

\section{I ntroduction}

A myocardial infarction (MI) is a life-threatening, life-changing event [1]. People who have suffered a MI are at heightened risk for a new cardiac event, making secondary prevention important. Successful rehabilitation after MI requires that patients receive the best possible information and education to enable them to follow treatment regimens and make informed decisions about necessary lifestyle changes.

Over the past decades, a multitude of studies have examined the information needs after a MI and have resulted in more or less standardized information lists and educational tools [2, 3]. Hospitalized patients often receive information through Published by Sciedu Press 
daily patient-nurse communication, both formal and informal $[4,5]$. Despite considerable efforts to ensure that the patient's information needs are met before hospital discharge, several studies claim that this goal is not reached [2, 3, 6, 7]. A recent study shows that even though information on symptom management and lifestyle changes was deemed most important for patients with MI, nearly $15 \%$ of them reported that no lifestyle changes were discussed during their hospital stay [8].

Little is known about how this discrepancy arises, but several studies have shown that nurses and patients differ in what information they consider most important, and that the nursing dialogue is often based on health-care providers' perception of what patients need to know [9]. Nurses generally either over- or underestimate the type and amount of information required during hospitalization [10]. Patients are not well prepared for what life will be like after discharge, and their first days at home are often characterized by uncertainty, anxiety and dejection [6]. Spouses report even higher levels of distress and anxiety than the patients themselves during the early recovery period [11]. Patients often find it difficult to identify relevant questions prior to discharge [12]. A literature review indicates that secondary prevention must build upon patients' own perceptions about their condition and the treatment they receive [13] and that patients' social context and emotional needs are often not taken into account adequately.

Studies in chronic care indicate that person-centered communication is necessary for shared decision making and to empower patients to take responsibility for their own health [14]. In person-centered communication, the patient's perspective is the foundation for the dialogue, and social, psychological and emotional factors are acknowledged as being equally important as somatic symptoms [2, 3, 9]. However, a trend towards speedier patient discharges has been suggested to be a barrier to using a patient-centered communication in acute care $[15,16]$, and lack of time has been cited as a hindrance to patient participation in MI care, by both patients and personnel [17].

The patients' involvement in decision making has been emphasized in recent years. Increasingly, professionals invite the owner of a problem to participate in decision making and problem solving, instead of just asking him or her to comply with their decisions. Covinsky et al. [18] found that poor communication and low patient participation in decision making during hospitalization was related to poorer health three months after a MI and delayed return to work. This was contradicted in a more recent study where higher patient involvement during hospitalization were not consistently associated with more desirable outcomes or with MI patient health and behaviour 6-10 weeks after hospital discharge [19].

Achieving patient participation is considered especially difficult during the initial, emergency phase of MI [19] and it primarily takes the form of information [17]. Nurses in a coronary care unit (CCU) put considerable effort in following guidelines and providing the best possible information to the patient. However, there is still a lack of insight into what the daily formal and informal patient-nurse communication means to the patient after an acute MI, to what extent the patient's values and expectations are taken into account, and whether the informational support is actually tailored to the patient's need in practice. Thus this study aims to explore the meaning of the patient-nurse communication during the hospital stay as narrated by MI patients.

\section{Participants and methods}

\subsection{Study design}

A qualitative approach with narrative interviews and a phenomenological-hermeneutic method was used to interpret the meaning of the patient-nurse communication after an acute MI. Participants were recruited during a period of two months from a CCU in a medium-sized Swedish hospital. Inclusion criteria were: a primary diagnosis of MI, in-patient in the CCU, and ability to speak Swedish. Patients that fulfilled these criteria were given an information letter by nurses working in the CCU. Then the first author contacted each potential participant and asked if they wanted to take part in the study. Ten patients (mean age 64.5) were included, No patient declined participation. The hospital stay lasted 4-7 days, during which no unusual complications were noted. The nurses delivered standardized information about MI, according to national guidelines, including information about medication, treatment and lifestyle changes. 
All interviews were conducted by the first author, in a quiet room outside the CCU within two weeks after discharge. The interviews lasted from 30 to 55 min. The opening question was: "Would you please tell me about your perceptions of the communication with the nurse during your hospital stay”. They were encouraged to talk about specific situations, and allowed to speak as freely as possible with a minimum of interruptions. Follow-up questions were asked, in order to expand on or clarify the narratives. This narrative interview approach is seen as a discourse between speakers and is a way for the interviewees to reflect on and understand their own experiences.

\subsection{Ethical considerations}

The study was approved by the regional Ethics Committee for Human Research in Stockholm, Sweden (Dnr: 20080117162713472), and conforms to the principles outlined in the Declaration of Helsinki. Verbal and written consent was obtained prior to all interviews.

\subsection{Data analysis}

All interviews were tape-recorded and transcribed verbatim. A phenomenological hermeneutic approach [20] inspired by Ricoeur's [21] "interpretation theory” was used for analysis. This form of interpretation is a dialectical movement between understanding the text as a whole and explaining its individual parts. The approach alternates between bringing the text close to the interpreter and distancing the interpreter from the text. Gradually a comprehensive understanding of what the text points to is achieved. The interpretation involves three phases: naive reading, structural analysis and critical interpretation [20].

A naive reading of all the transcribed interviews was done to obtain a first impression of the meaning as a whole. This first re-reading was made as open-minded as possible without any analysis of the text. The first naive understanding was formulated in everyday language aimed to guide the structural analysis. Then the structural analysis was performed; the interview texts were divided into meaning units (i.e. a sentence, part of a sentence, or several sentences with a related meaning content) which were then condensed while still preserving their core. The condensed meaning units were further condensed and abstracted to form one main theme consisting of five sub-themes. The themes and sub-themes were reflected on with the naive understanding in mind, in order to validate the naive understanding. This was an ongoing process with a dialogue between the authors until the structural analysis validated the naive understanding.

During the critical interpretation, a text were re-read and interpreted in relation to the researchers' pre-understanding, the naive understanding, and the themes (the results of the structural analysis) and a comprehensive understanding, of the interview texts as a whole, was formulated.

\section{I nterpretation and results}

\subsection{Naive reading}

The nursing dialogue gave patients a safe point to hold on to when their everyday lives collapsed without warning. In the acute phase the nursing dialogue enabled patients to process fear and anxiety by talking about their worries and repeatedly reflecting over the situation. To be surrounded by a relaxed and permissive atmosphere, where all kinds of questions could be asked, made it possible to build up a trustful relationship with the nurse. The foundation for the trustful relationship was the nurse's presence (physical and emotional) and accessibility for communication. Without an established relationship, patient-nurse communication was solely an exchange of information, and the opportunity for acquiring knowledge through personal questions and calm reflection was lost. The communication became a support to mobilize commitment to lifestyle changes. If the next of kin were included in the communication a feeling of shared understanding arose and the family member became a safe point to rely on after discharge. 


\subsection{Structural analysis}

The results from the structural analysis resulted in one main theme and five subthemes that are presented below and illustrated with quotations. The patient-nurse communication after an acute MI means "a secure place on the trajectory from chaos to a new order" and includes: security in an insecure situation; a trustful relationship; acquiring knowledge; support to mobilize commitment to change and a supportive link to relatives.

\subsubsection{Security in an insecure situation}

Being struck down by an acute and serious disease meant a complete loss of control. In this situation, the nursing dialogue became a safe point to hold on to. That nurses were constantly present, providing explanatory information, was crucial for the patients in the first chaotic phase. "What surprises me is that I wasn't at all worried anymore; [the nurses] were calm, objective, professional, so to speak.”

The nurse's advice and short-range, concrete instructions such as "do it this way", were like a lifeline when the body signals were unfamiliar and frightening. The patients describe feeling betrayed by their body, and were afraid of being "let down" again. The nursing dialogue provided patients the security they needed to test the limits of their physical capacity and regain confidence in their own body. One person said, "Of course I was worried. Not that I was having panic attacks all the time but I was worried and kept thinking I hope nothing happens and I have another setback. You don't go around constantly brooding but you live with your fear all the time, especially when you're alone.”

\subsubsection{A trustful relationship}

The patients described being met with warmth and respect, and felt that their expectations, beliefs and values were taken into account. A mixture of skill and humor created an open atmosphere, which facilitated broaching difficult topics. Trust was built up when the nurse was present, accessible and showed interest in the patients' concerns. When nurses entered the room for unscheduled visits they conveyed that they were there to share the patients' experiences. "If I start to have doubts or wonder about something, all I have to do is call, I've felt that all this time. There are no problems. It's like what some of the nurses say: that's what we're here for and that's what so great, it gives me a feeling of security.”

The physical environment also played a significant role for a trusting communication. Privacy made it possible to share thoughts and feelings and to ask questions of a personal nature. On the other hand, a non-trusting atmosphere arose when the nurse was under stress or unavailable. In that atmosphere the communication failed. If nurses talked about the scarcity of healthcare resources, the patients only took up their most basic questions, of purely practical nature. One person said, “They have work to do and you don’t want to be a burden. So I didn’t say anything”.

Awkward situations could arise if the patient received contradictory information. Inconsistent or poorly coordinated information led to confusion and the patients lost confidence in the nurses' ability.

\subsubsection{Acquiring knowledge}

The patients described their need for knowledge about the disease and how to handle their new situation. The information given during medical rounds was sometimes difficult to understand and the doctors gave an impression of being in a hurry. The patients found nurses more accessible and viewed patient-nurse communication as an opportunity to ask "stupid" questions and get explanations for difficult and complicated medical terms. Such communication helped them comprehend the consequences for their everyday life. Some patients had difficulty remembering their discussions with the nurses. "There was a nurse here talking, but what we talked about I hardly remember. It was a bit about the disease and risk factors and that sort of thing”. The way in which nurses entered into a communication seemed crucial for how the patients would receive the information. Many patients described that the opening sentence could make them lose interest. He (the nurse) opened with: "No doubt you've heard this before". This made it clear from the start that the communication would be routine, standardized, and the patient did not remember any more from that particular occasion.

Many participants expressed a need for a different kind of knowledge than what was delivered. They perceived that the nurses wanted to convey their standard information about risks and lifestyle changes, while the patients wished to discuss 
the implications from an emotional perspective, and as a question of quality of life. Patients felt that there was no time for reflection; "They talked about smoking and exercise and eating properly. But I know all of that anyway. So it's, you know, it’s like you hear it too much. But "how do you do it?"

Some patients described the communication as a play where both actors knew their parts: the nurse gave certain information and the patient's role was to listen, while both knew that the information would not lead to any behavioral changes. Feelings of guilt and of being considered "a hopeless case” were apparent. "I felt I had no right to complain // I was ashamed of myself // That's why I didn't want to say anything”. On the other hand, lack of knowledge led to uncertainty and inactivity during convalescence, since patients did not know what changes they needed to make. It was important to know where to turn with questions that arose after discharge: a phone number to call served as a safety net.

\subsubsection{Support to mobilize commitment to change}

Supportive communication arose when patients felt confirmed as worthy individuals, entitled to their own thoughts and opinions. Feeling invited to participate in the choice of lifestyle changes, and how those changes should be implemented and maintained, was a necessary condition for motivation to change. An empathetic and tolerant attitude opened up for communication about worries and fear of failure. Changing unhealthy habits triggered a kind of mourning for all the good things in life that were now forbidden: "Of course sometimes you think it's hell but I know what this is all about, that I shouldn’t drink and I shouldn't smoke. Now I know ... everything is off limits.” Getting nurses’ support to set up personal action plans was one way to translate knowledge into practice. Conversations where the nurse primarily emphasized the health benefits of a changed behavior strengthened the motivation to change. When the nurse posed questions and discussed potential solutions, the patients grew more confident in their ability to live their lives after returning home.

\subsubsection{A supportive link to relatives}

Participants described the central role of relatives. The patients' uncertainty in a new life situation made support from relatives important during the recovery process. It was perceived as a good safety precaution to have a loved one participate in the patient-nurse communication and thus share the same information. This also reduced the risk that family members' own fear and anxiety would impede the patients' progress and rehabilitation. One person said, “Also, everyone around you feels concerned about you in this sort of situation. My wife was also there for this conversation and it was good that she could be there. This can be recommended and my daughter was with us too and she also thought it was good. They understand better that I need to exercise and be active. I mean, you have to keep on living your life.” When the nurse invited the entire family into the conversation, this created a sense of security not only for the patients but also for their relatives. There was another person who had received the same information, someone to turn to when either the patient or the relative wondered if they remembered or understood things correctly.

\subsection{Critical interpretation and reflections}

From the critical interpretation, a comprehensive understanding of meanings of the nursing dialogue after an acute MI as narrated by patients was expressed as follows: the nursing dialogue is a firm point to hold on to during the initial chaos after a MI and throughout hospitalization. The need for communication varied over time. Initially, the communication consisted of brief instructions or non-verbal signals about the patients' basic needs. Later, communication served for the development of a trustful relationship, as a facilitator for acquiring new knowledge, and as a support to mobilize commitment to change, and thus establishing a healthier lifestyle. The nursing dialogue was also understood as a supportive link to relatives and in this way played a crucial role for patients returning home.

Our interpretation indicates that patient-nurse communication was extremely important for patients' recovery after a MI and that communication could be patient-centered even in the emergency phase. Reaching that understanding, we find it fruitful to reflect upon our findings in light of the ethics of Lögstrup and the concepts of trust and power in situations of vulnerability. 
A trustful relationship - the foundation for person-centeredness in the acute phase was largely achieved by non-verbal communication, when the nurse was constantly present and available in the patient's room. The nurse's brief words to calm the patient or to clarify information or specific instructions also meant security for the patient. According to McCabe [22] the presence of nurses inspires patient security in a communication when nurses also are aware of what is unspoken what is felt, thought, and meant. The acute phase after an MI is a vulnerable situation where the patient is faced with matters of life and death. Talseth et al [23] disclosed that in vulnerable situations, trusting and being trusted is a precondition for being open and, like the patients in our study, literally leaving one's body in someone else's custody. By doing this the person also transfers power into the nurse's hands [24]. However, trust is risky and makes the "trustier" vulnerable. The other person may retain that which has been entrusted, or simply discard it. Therefore it is important to reflect upon the situations of power imbalance in patient-nurse communication that have emerged from this study-Such imbalance appeared when patients were confused, in fear or shock in the emergency phase after a MI; in their inferior knowledge about their disease or how to handle it; and in their guilt over unhealthy habits. In addition, the structural power imbalance inherent in the health care system makes it difficult for patients to challenge nurses' assessments and advice. In the light of the ethics of Lögstrup [25] this imposes an unspoken ethical demand on nurses (p. 22): they must be aware of the patients' dependency and vulnerability and the gap between their own and the patients' view. Most activities in a CCU are disease-oriented, focused on the patients' symptoms, test results and treatments. The same phenomenon was noted in chronic care, where nurses got stuck in disease-oriented activities, instead of starting from the patient's perspective, and focusing on their understanding of the situation [14]. Workload and lack of time is frequently cited as an argument for not entering into person-centered communication. But it is only partly a question of time. Person-centered communication does not need to be time consuming [22, 26]. Rather, our study indicates that the most important thing was that nurses show willingness to listen rather than to come up with solutions. This is in line with the findings of Talseth et al [23] where "being met" in vulnerable situations, means to be confirmed in a nonjudgmental way, with one’s pre-understanding, fears and concerns.

Even though nurses theoretically acknowledge the need to involve the patient in a person-centered communication, they seem to forget that patients have expert knowledge about their own health assets, and thus overlook the potential for joint problem solving [27]. This study highlights several prerequisites for person-centered communication. First, there was a need for a private space where the patient can feel safe to express thoughts and worries and where nurses can focus on the communication. A second barrier to person-centered communication in acute care is that medical advances have significantly shortened the hospital stay in recent years [9]. Therefore nurses are keen on providing standardized, evidence-based information according to guidelines. However, as Grimen [24] expresses it "what makes routines helpful also makes them dangerous" (p. 20) since the individual perspective is often lost. Another barrier might be deficiencies in nurses' communication skills. When the nurse started a conversation by saying "No doubt you've heard this before...", the patient did not feel invited into a dialogue. When the nurse merely delivered information about MI and lifestyle changes without involving the patient as the owner of the problem, it was hard to find motivation for lifestyle changes. Eldh et al [28] describes the patient's non-participation as arising from a feeling of not being in control of the situation, and that your opinion does not even count. In an extensive concept analysis on health assets, Rotegård et al [29] identified motivational strength as an important asset for lifestyle changes. The nursing dialogue strengthens the patients' motivation and by supporting deeper reflection on their situation and their options for implementing changes. Many patients wanted more emphasis on the benefits of lifestyle changes and support to clarify goals in a personal action plan, instead of just information on the consequences of unhealthy habits. A dialogue focusing on the patients' health assets and skills gives them responsibility for their own agenda, and might yield sustainable lifestyle changes [29].

Patients in this study expressed a need for acquiring knowledge, but the timing was important. In the early chaotic state, when existential reflections and worries were commonplace, patients were not receptive to information about lifestyle changes. However, as in the study by Decker et. al. [30] the patient's need for information and desire for participation both increased during their hospitalization. In line with previous studies, nurses' presence decreased as the patient's condition improved [13, 18]. Reduced availability has often been attributed to lack of time because of slimmed-down organization. Thus routines that ensure nurses' presence, and integrate person-centered communication in daily clinical practice are 
highly warranted throughout the entire rehabilitation process, to serve patients' learning needs, and to implement self-management and life skill training.

Finally, involving relatives in the patient-nurse communication was experienced as another way to meet the patient's need for support after discharge. Relatives often perceive the patient's arrival home from hospital as a worrying and anxious time [6], and relatives who have not been involved in the patient-nurse communication may be an obstacle rather than a support in the rehabilitation process [6, 31].

Although our study was limited to a small sample of patients, these few participants represented different backgrounds, genders, and ages, and could be regarded as representative of a population with experience of patient-nurse communication after a MI. Whether these findings are transferable to patients in other and larger hospitals or other countries remains to be shown in other studies.

\section{Conclusion and implications}

These results highlight that patient-nurse communication based on the patient's view is possible in acute care after MI, and is an issue of attitude rather than time. Trust lays the foundation for a person-centered communication and is developed through the nurse's presence and availability not only in the emergency phase, but throughout hospitalization. Such communication is maintained through everyday bedside conversations which give the patient, disoriented by the MI, a stable point from which to acquire new knowledge and a sense of what happened, and to mobilize his or her health assets and motivational strengths for lifestyle changes. This study revealed that the patients preferred to participate in discussions focused on personal action plans with emphasis on the patient's health assets and benefits of lifestyle changes rather than merely receiving standardized information. Successful rehabilitation may require further support after discharge and this may be facilitated if the patient's relatives are also included in the patient-nurse communication and decision making.

\section{Source(s) of support}

The authors disclosed receipt of the following financial support for the research and authorship of this article: R\&D Center/ Center for Clinical Research Sörmland County Council.

\section{Conflicting I nterest}

There are no conflicts of interest to declare.

\section{References}

[1] Fridlund B, Hildebrandt L, Hildingh C, Lidell E. Status and trends in Swedish dissertations in the area of cardiovascular nursing. Eur J Cardiovasc Nurs. 2007 Mar; 6(1): 72-6. PMid: 16782406 http://dx.doi.org/10.1016/j.ejcnurse. 2006.04.005

[2] Scott JT, Thompson DR. Assessing the information needs of post-myocardial infarction patients: a systematic review. Patient Educ Couns. 2003 Jun; 50(2):167-77. PMid: 12781932

[3] Smith J, Liles C. Information needs before hospital discharge of myocardial infarction patients: a comparative, descriptive study. J Clin Nurs. 2007 Apr; 16(4):662-71. PMid: 17402947 http://dx.doi.org/10.1111/j.1365-2702.2006.01689.x

[4] Propp KM, Apker J, Zabava Ford WS, Wallace N, Serbenski M, Hofmeister N. Meeting the complex needs of the health care team: identification of nurse-team communication practices perceived to enhance patient outcomes. Qual Health Res. 2010 Jan; 20(1):15-28. PMid:20019348 http://dx.doi.org/10.1177/1049732309355289

[5] Johansson A, Dahlberg K, Ekebergh M. Living with experiences following a myocardial infarction. Eur J Cardiovasc Nurs. 2003 Sep; 2(3):229-36. http://dx.doi.org/10.1016/S1474-5151(03)00033-1

[6] Hanssen TA, Nordrehaug JE, Hanestad BR.A qualitative study of the information needs of acute myocardial infarctionpatients, and their preferences for follow-up contact after discharge. Eur J Cardiovasc Nurs. 2005 Mar; 4(1):37-44. PMid:15718191 http://dx.doi.org/10.1016/j.ejcnurse.2004.11.001

[7] Arnetz JE, Arnetz BB. Gender differences in patient perceptions of involvement in myocardial infarction care. Eur J Cardiovasc Nurs. 2009 Sep; 8(3):174-81. PMid:19101209 http://dx.doi.org/10.1016/j.ejcnurse.2008.11.002 
[8] Nakano A, Mainz J, Lomborg K. Patient perception and assessment of admission to acute cardiac care unit. Eur J Cardiovasc Nurs. 2008 Mar; 7(1):10-5. PMid:17602872 http://dx.doi.org/10.1016/j.ejcnurse.2007.05.002

[9] Timmins F, Kaliszer M. Information needs of myocardial infarction patients. Eur J Cardiovasc Nurs. 2003 Apr; 2(1): 57-65. http://dx.doi.org/10.1016/S1474-5151(02)00089-0

[10] Rose JH, Bowman KF, Kresevic D. Nurse versus family caregiver perspectives on hospitalized older patients: an exploratory study of agreement at admission and discharge. Health Commun. 2000; 12(1):63-80. PMid:10938907 http://dx.doi.org/10.1207/S15327027HC1201_04

[11] Jones ID, Karapiperis V, Bowman L, Duggan H, Jones D, Johnson M, et al. Does formal psychoeducational support influence anxiety and depression levels in cardiac patients and their relatives?: a pilot study. J Cardiopulm Rehabil. 2006 May-Jun; 26(3): 172- 5. PMid:16738457 http://dx.doi.org/10.1097/00008483-200605000-00011

[12] Burney M, Purden M, McVey L. Patient satisfaction and nurses' perceptions of quality in an inpatient cardiology population. J Nurs Care Qual. 2002 Jul; 16(4):56-67; quiz 8-9. PMid:12125905 http://dx.doi.org/10.1097/00001786-200207000-00009

[13] Attebring MF, Herlitz J, Ekman I. Intrusion and confusion--the impact of medication and health professionals after acute myocar dial infarction. Eur J Cardiovasc Nurs. 2005 Jun; 4(2):153-9. PMid:15904886 http://dx.doi.org/10.1016/j.ejcnurse.2005.02.001

[14] Zoffmann V,Harder I,Kirkevold M. A person-centered communication and reflection model: sharing decision-makingin chronic care. Qual Health Res. 2008 May; 18(5):670-85. PMid:18223158 http://dx.doi.org/10.1177/1049732307311008

[15] Langewitz WA, Eich P, Kiss A, Wossmer B. Improving communication skills--a randomized controlled behaviorally oriented intervention study for residents in internal medicine. Psychosom Med.1998 May-Jun; 60(3):268-76. PMid: 9625213

[16] Graugaard PK, Finset A. Trait anxiety and reactions to patient-centered and doctor-centered styles of communication: an experim ental study. Psychosom Med. 2000 Jan-Feb; 62(1):33-9. PMid:10705909

[17] Hoglund AT, Winblad U, Arnetz B, Arnetz JE. Patient participation during hospitalization for myocardial infarction: perceptions among patients and personnel. Scand J Caring Sci. 2010 Sep; 24(3):482-9. PMid:20230518 http://dx.doi.org/10.1111/j.1471-6712.2009.00738.x

[18] Covinsky KE, Chren MM, Harper DL,Way LE, Rosenthal GE. Differences in patient-reported processes and outcomesbetween men and women with myocardial infarction. J Gen Intern Med. 2000 Mar; 15(3):169-74. PMid:10718897 http://dx.doi.org/10.1046/j.1525-1497.2000.01269.x

[19] Arnetz JE, Winblad U, Hoglund AT, Lindahl B, Spangberg K, Wallentin L, et al. Is patient involvement during hospitalization for acute myocardial infarction associated with post-discharge treatment outcome? An exploratory study.Health Expect. 2010 Sep; 13(3):298-311. PMid:20579120

[20] Lindseth A, Norberg A. A phenomenological hermeneutical method for researching lived experience. Scand J Caring Sci. 2004 Jun; 18(2):145-53. PMid:15147477 http://dx.doi.org/10.1111/j.1471-6712.2004.00258.x

[21] Ricœur P. Interpretation theory: discourse and the surplus of meaning. Fort Worth, Texas: Texas Christian U.P.1976.

[22] McCabe C. Nurse-patient communication: an exploration of patients' experiences. J Clin Nurs. 2004 Jan; 13(1):41-90. PMid:1468 7292 http://dx.doi.org/10.1111/j.1365-2702.2004.00817.x

[23] Talseth AG, Gilje F, Norberg A. Being met--a passageway to hope for relatives of patients at risk of committing suicide: a pheno menological hermeneutic study. Arch Psychiatr Nurs. 2001 Dec; 15(6):249-56. PMid:11735075 http://dx. doi.org/10.1053/apnu.2001.28687

[24] Grimen H. Power, trust, and risk: some reflections on an absent issue. Med Anthropol Q. 2009 Mar; 23(1):16-33. PMid:19449710 http://dx.doi.org/10.1111/j.1548-1387.2009.01035.x

[25] Lögstrup KF, H; MacIntyre, AC. The ethical demand: University of notre dame press. 1997.

[26] Chant S, Jenkinson T, Randle J, Russell G. Communication skills: some problems in nursing education and practice. J Clin Nurs. 2002 Jan; 11(1):12-21. PMid: 11845748 http://dx.doi.org/10.1046/j.1365-2702.2002.00553.x

[27] Whittington D, McLaughlin C. Finding time for patients: an exploration of nurses' time allocation in an acute psychiatric setting. J Psychiatr Ment Health Nurs. 2000 Jun; 7(3):259-68. PMid:11249320 http://dx.doi.org/10.1046/j.1365-2850.2000.00291.x

[28] Eldh AC, Ehnfors M, Ekman I. The phenomena of participation and non-participation in health care--experiences of patients attending a nurse-led clinic for chronic heart failure. Eur J Cardiovasc Nurs. 2004 Sep; 3(3):239-46. PMid:15350234 http://dx.doi.org/10.1016/j.ejcnurse.2004.05.001

[29] Rotegard AK, Moore SM, Fagermoen MS, Ruland CM. Health assets:a concept analysis. Int J Nurs Stud. 2009 Apr;47(4):513-25. PMid:19819452 http://dx.doi.org/10.1016/j.ijnurstu.2009.09.005

[30] Decker C, Garavalia L, Chen C, Buchanan DM, Nugent K, Shipman A, et al. Acute myocardial infarction patients' information needs over the course of treatment and recovery. J Cardiovasc Nurs. 2007 Nov-Dec; 22(6):459-65. PMid: 18090186

[31] Thorsteinsson LS. The quality of nursing care as perceived by individuals with chronic illnesses: the magical touch of nursing. J Clin Nurs. 2002 Jan; 11(1):32-40. PMid: 11845753 http:// dx.doi.org/10.1046/j.1365-2702.2002.00575.x 